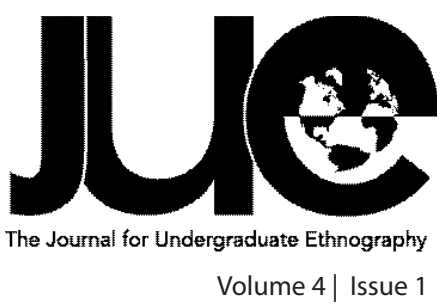

\title{
A Campaign of Intersections: Evaluating Perceptions of the Our City of Colours LGBTQ Posters in Metro Vancouver
}

\author{
Simon Lam \\ Simon Fraser University, scl23@sfu.ca
}

\section{ABSTRACT}

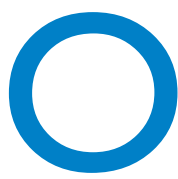

ur City of Colours (OCC) is a Vancouver-based group looking to raise the visibility of, and address the issues facing lesbian, gay, bisexual, transgender, and queer (LGBTQ) people in various linguistic and cultural communities.

In November 2011, the group released a series of 6 posters online featuring LGBTQ people who identified with a particular cultural background. This paper seeks to analyze the perceptions of these posters from the OCC team and people outside the team. Ultimately, this is an early evaluation of whether OCC can meet its mandate in conveying their message to linguistic and cultural communities. Through the use of participant observation, interviews, focus groups, archival data analysis, and content analysis, the OCC posters were found to have a relatively positive impact in increasing visibility of LGBTQ people and issues. However, participants noted that using more cultural references and having more romantic images to solidify the LGBTQ message could further strengthen the impact of the posters. There is also the need for the posters to be directed towards the older generation as many of the participants identify the older generation as a key demographic for receiving positive LGBTQ messages.

Keywords: ethnicity, homophobia, culture, awareness, LGBTQ 


\section{INTRODUCTION}

The cries of concerned parents dominated the newspapers in Burnaby, British Columbia during the summer of 2011 when the school board debated the inclusion of an anti-homophobia policy in Burnaby schools (Moreau 2011a). This policy aimed to improve the education of sexual orientation and gender identity in classrooms. Eventually, the board decided to implement the policy, much to the dismay of a culturally diverse group of upset parents calling themselves the Parents' Voice. This group was worried that the policy would force children to question their sexuality and turn children into homosexuals or transgender people (Moreau 2011b). This lack of understanding of lesbian, gay, bisexual, transgender, and queer (LGBTQ) issues is concerning as it unfairly stereotypes a certain group (i.e., the LGBTQ communities) based on false information. The controversy over the anti-homophobia policy highlights the need to educate communities and people on LGBTQ issues through awareness projects and campaigns. A few months before the incident, a grassroots project called Our City of Colours (OCC) was created with a mission "to promote the visibility of, and address the issues facing lesbian, gay, bisexual, transgender and queer people in a variety of linguistic and cultural communities" (Our City of Colours 2011). They proposed to accomplish this by distributing posters with positive images and messages featuring people who self-identify as LGBTQ and as part of a linguistic and/or cultural community. This study seeks to analyze perceptions of the OCC posters from October 2011 to November 2011.

\section{OUR CITY OF COLOURS}

The project grew from a gay men's workshop where participants were asked to propose projects addressing the needs of the gay men community. One of the participants came up with the idea to raise awareness of gay men in ethnic communities that deny or reject the existence of homosexuals. This participant, a 22 year-old Simon Fraser University (SFU) student, decided to initiate a project based on his idea, but expanded it to include LGBTQ people (not just gay men) and to broader communities (not just ethnic communities). In March 2011, he gathered individuals from the gay men's workshop, including myself, to be a part of a project called Our City of Colours. The name symbolizes the diversity of humans as well as our desire to connect cultures together regardless of a person's sexuality. At the time, the
OCC team comprised of ten gay men from a variety of different backgrounds including Chinese, Hispanic, Persian, and Punjabi. As mentioned, the team seeks to raise awareness and to promote positive images of LGBTQ individuals in a variety of linguistic and cultural communities. With this particular project, they raised awareness by distributing posters across Metro Vancouver. These posters feature people from a variety of ethnicities and backgrounds who identify as LGBTQ. During the time of the study, the posters were primarily released online through OCC's Facebook page.

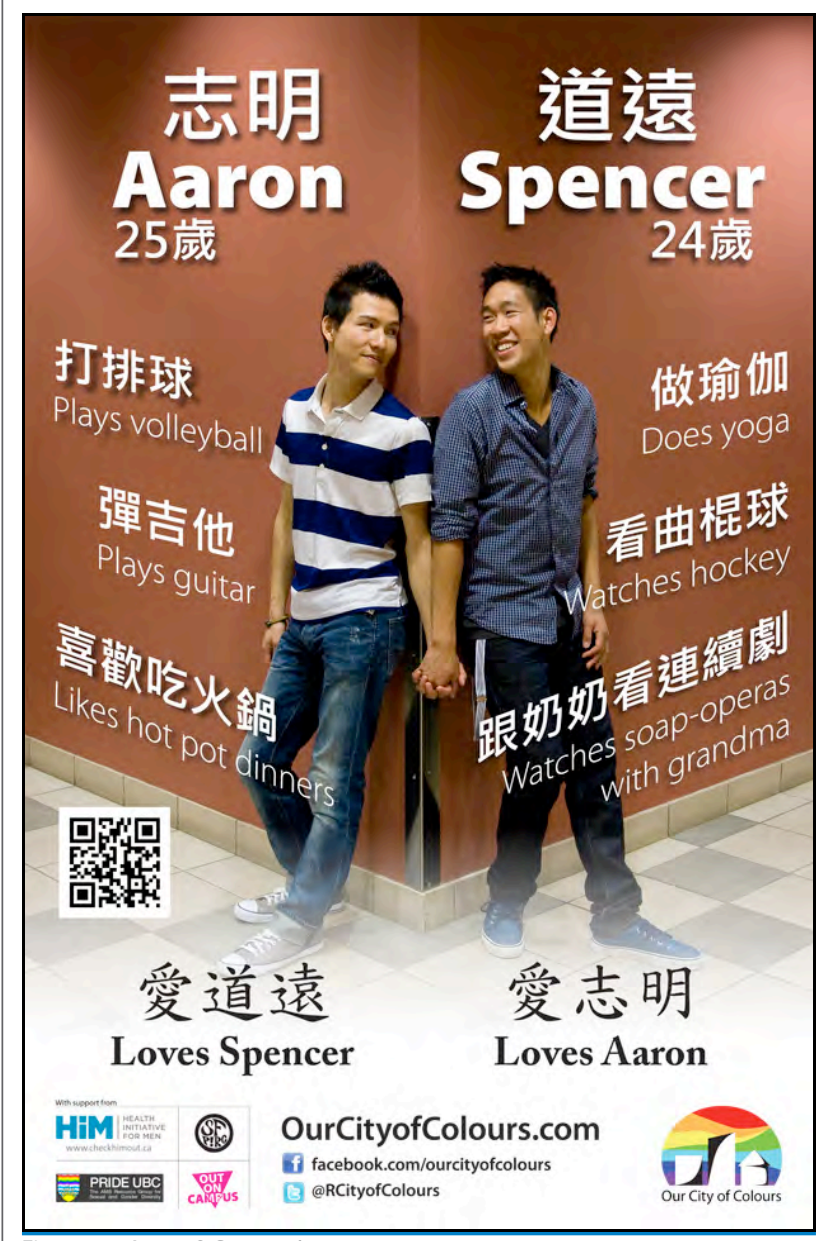

Figure 1-Aaron \& Spencer's poster 
It is important to mention that during this time, I was deeply involved in the group and assisted in creating the images and messages of the posters. I have tried to remain unbiased for this study, but given the nature of qualitative research, my biases may have emerged in the findings. However, multiple methods were used to encourage the incorporation of various perspectives in the conclusions of the study. In addition, my role within the organization meant that I was the gatekeeper and it also allowed me to build rapport with the participants. This rapport contributed in creating a safe space for conversations regarding LGBTQ people and issues.

\section{HOMOPHOBIA IN ETHNIC COMMUNITIES}

The literature shows that some ethnic communities hold a negative perspective of homosexuality. I acknowledge that the term ethnic has various definitions. For the purpose of this study, ethnic communities will refer to non-White communities. A number of studies indicate that LGBTQ people in ethnic communities view their culture as less accepting towards homosexuality compared to Western European influenced communities in Canada and the United States. (Chung and Szymanski 2006, 67-93; Chan 1989, 16-20; Mireshghi and Matsumoto 2008, $372-$ 376). According to Chung and Szymanski (2006, 67-93), Asian culture is seen to be more conservative and possess limited tolerance for LGBTQ individuals. As a result, LGBTQ Asians are less likely to come out to their parents because of the perception that Asian culture is less accepting of homosexuals.

Several studies reiterate this theme of a lack of support from ethnic communities for LGBTQ people (Hooghe et al. 2010, 384-400; Abraham 2009, 79-97; Boulden 2009, 134-150; Hooghe et al. 2010, 49-71). One reason for the lack of support is the perceived clash of different values between the two cultures, that being the ethnic culture and the LGBTQ culture. The emphasis on traditional values like focusing on family has resulted in a negative view of homosexuality as the ethnic community believes homosexuals cannot maintain a family (Boulden 2009, 134-150; Hooghe et al. 2010, 49-71; Han 2007, 51-67; Mao, Mccormick, and Van 2002, 419-430). For Hmongs in the United States, males are expected to fulfill their patriarchal role as the dominant individual in the household and make all the decisions. The inability for some gay Hmong to live up to this cultural role has resulted in rejection by the Hmong community
(Boulden 2009, 134-150).

With the lack of support for LGBTQ individuals, it is not surprising that some ethnic communities refuse to openly discuss sexuality and instead, opt to avoid the subject all together. Han (2007, 51-67) found that the Asian and Latino communities do not have any positive words for gay. On the other hand, there are several derogatory terms to describe LGBTQ individuals, including a term analogous to transvestite (62). Boulden (2009, 134-150) uncovered a similar phenomenon in the Hmong community where no word exists to describe an LGBTQ person. Muslims face the same problem according to participants in Abraham's (2009, 79-97) study of queer Muslims in Australia. One participant mentioned that his friends reacted with disbelief when the participant came out as gay; to his friends, a queer Muslim simply did not exist (88).

Given the lack of acknowledgement by some ethnic communities towards non-heterosexuals, some LGBTQ people feel isolated from their own ethnic culture. An online survey conducted by Lui et al. (2009, 247-266) on LGBTIQ (addition of I is intentional and stands for intersexual) South Asians in southern California discovered that participants felt more alienated in their own cultural community than the LGBTIQ community. In total, $70 \%$ of participants also experienced homo/trans/biphobia from the South Asian communities and $72 \%$ felt isolated or lonely (258). The lack of support by the ethnic community is further echoed by a study from Szymanski and Gupta (2009, 267281) on Asians in the United States. Many of the participants felt a persistent sense of cultural heterosexism where heterosexist norms were upheld at the expense of support towards LGBQ (lack of T is intentional) people. Brian O'Neill (2011) found a prevalent influence of heterosexist values in his study of LGB (lack of T and Q is intentional) newcomers in Canada. He notes that participants experienced heterosexism in their communities which prevented them from accessing services like immigration assistance and support for their struggles with their sexuality. In addition, newcomers also experienced racism within LGB communities.

Furthermore, there is an emphasis on Muslims and Asians to follow the collective lifestyle of their community and de-emphasize the individualistic culture prevalent in Western countries. Hooghe, Claes, Harell, Quintelier, and Dejaeghere (2010, 49-71) discovered that Muslims are expected to care for the fam- 
ily and their future generations. Thus, the LGBTQ identity does not simply impact the individual, but also plays a huge influence over the family and the community. A similar line of thinking is found within the Asian community (Han 2007, 51-67; Mao, Mccormick, and Van 2002, 419-430).

However, some of the literature cautions against blaming ethnicity for homophobia. One study in Belgium looked at the extent to which attitudes toward homosexuals differ between young people of foreign origin and native-born Belgians (Hooghe et al. 2010, 384-400). They found that young people of foreign origin had significantly more negative attitudes toward homosexuals than Belgian youths. The authors also discovered that ethnicity was not directly related to sexual prejudice; instead, a feeling of hostility from social institutions contributed to homophobic attitudes (Teney and Subramanian 2010, 151-173). Another study also cautioned against generalizing homophobic attitudes to all immigrants. Nearly 10,000 youths from Belgium and Canada answered several questions regarding their beliefs about gay rights activists (Hooghe et al. 2010, 384-400). The authors found that youth born outside of Canada or Belgium were less supportive of gay rights activists compared to native-born youths. Again, the authors are careful to distinguish between inherent hostility by immigrants and specific characteristics of the immigrant community that can lead to homophobic attitudes. They posit that immigrant communities may be more religious, leading to hostile attitudes toward homosexuality. In addition, Gallor and Fassinger's (2010, 287-315) study on lesbians and gay men found that ethnic minority participants and Caucasian participants have a similar level of satisfaction regarding social support.

The literature clearly indicates that there are negative perspectives towards LGBTQ people in ethnic communities. LGBTQ people are often silenced and their voices are not heard by the community. With the traditional roles revolving around heterosexual norms, some LGBTQ people risk being ostracized due to a perceived inability to live up to these roles. As a result, many ethnic LGBTQ people feel isolated from their ethnic community. Thus, there needs to be more awareness and education of LGBTQ people and issues in various ethnic communities. It is also important to avoid labelling all ethnic communities as homophobic. Several studies found that it is not the culture that is homophobic but rather, specific characteristics that can be found in all cultures. The purpose of the OCC posters is to initi- ate dialogue in various communities, including ethnic communities, as a way to improve understanding and to present positive messages and images of LGBTQ people.

\section{POSTERS AND ACCULTURATION}

Several studies have shown that poster campaigns can be effective in educating the public and raising awareness on various topics, like improving safety on shipyard scaffolds, preventing campus violence against women, and decreasing the amount of passive smoking (Etter and Laszlo 2005, 190-198; Saarela 1989, 177-185; Potter et al. 2009, 106-121). On the other hand, another study found that only a third of participants remembered content on a poster (Pulley et al. 2007, 233-241). The issue is how effective poster campaigns are in general, that is, do people acknowledge the messages within posters? An initial look at the effectiveness of OCC posters is important to determine whether more posters should be produced in the future. In addition, it is pertinent to determine whether these posters are capable of generating discussions of LGBTQ issues in linguistic and cultural communities. This study is an early evaluation of OCC's mission and to what extent they will be able to achieve their mandate. Specifically, it will look at whether the OCC posters can raise awareness of LGBTQ people and issues in linguistic and cultural communities, and as a result, encourage people in these communities to talk about these topics.

Ideally, the posters will be the first steps towards acculturation, a concept emanating from John W. Berry (2005, 697-712). This concept provides a framework of how LGBTQ communities and cultural communities can interact with each other. Although much of the work regarding acculturation is for ethnocultural communities, it could also be applied to LGBTQ communities as they have their own cultures. Berry maintains that acculturation, or the process by which two cultural groups integrate with each other, involves actions from both groups rather than a dependence on one to act. In this context, ethnocultural communities would adopt values of respecting LGBTQ people while LGBTQ communities will accommodate different cultural values and attitudes. Awareness would be the first step towards a goal of acculturation. Without awareness, there is no acknowledgement that acculturation should take place between LGBTQ communities and ethnocultural communities. OCC aims to initiate this first step through their posters. 


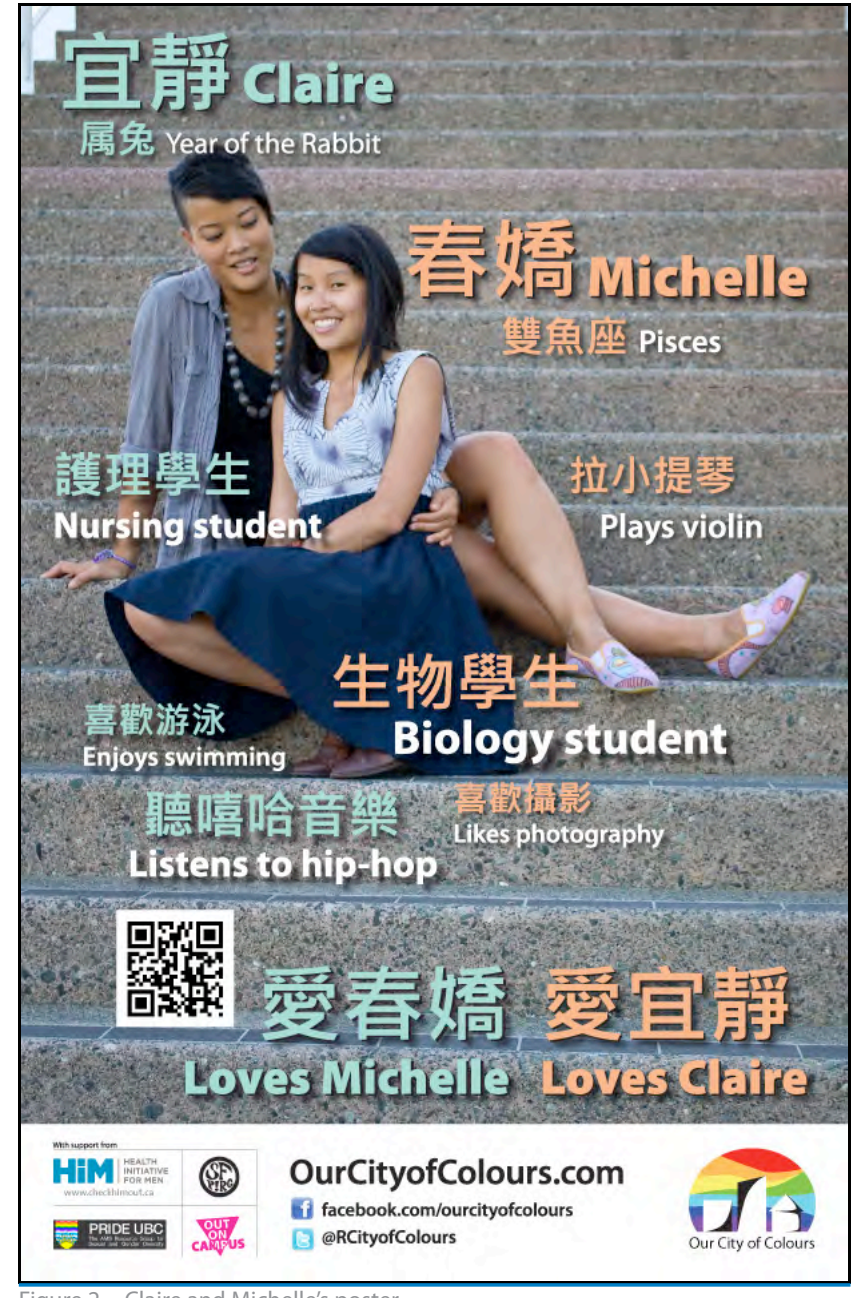

Figure 2-Claire and Michelle's poster

Thus, this paper (and the first phase of a participatory action project) aims to determine whether the posters are a step in the right direction in raising awareness of LGBTQ people and issues. In order to evaluate whether OCC is able to achieve this, the paper seeks to answer the following questions:

1. How does the Our City of Colours team want their post ers to be perceived by residents of Metro Vancouver?
2. What are some of the perceptions of the posters from people outside of the Our City of Colours team when the posters were initially released online in November 2011?

3. How do the reactions from people outside the Our City of Colours team relate to how the team want the posters to be perceived? 
These questions look to gather perceptions and reactions from a diverse range of people to evaluate the effectiveness of the posters. As such, it is important to collect a variety of opinions regarding how the posters impact people's attitudes regarding LGBTQ people and issues. These opinions will dictate whether the posters are successful and by association, the success of the advocacy work found within the posters.

\section{METHODS}

The purpose of this study is to gauge perceptions of the OCC posters from people within the team and people outside the team. Thus, multiple methods were used to ensure that I was able to obtain data on how the posters were perceived by various groups. The use of multiple methods also helped balance my substantial involvement with OCC and provide unbiased feedback to the posters. Through the use of methods like participant observation, interviews, focus groups, and archival analysis, I was able to study in-depth discussions on important themes and topics. On the other hand, content analysis on online materials brought forth various uncensored reactions to the posters. Overall, this study tried to gather a wide array of opinions in forming an informative conclusion.

Each participant signed an informed consent form which meant the participant recognized the ethical issues involved and how I planned to protect their identity. Their names will be kept confidential as well as any other specific characteristics that could be used to identify them. Interviews were recorded, but were destroyed after the research was completed. However, it is important to note that the names of the individuals involved in OCC are visible on OCC's Facebook page and appeared in various news articles. This means that people may be able to identify certain OCC team members based on the data presented in my paper. With the amount of publicity, I asked certain OCC members if they wished to have their name listed or if they would prefer to remain anonymous. As such, Darren Ho, the founder of OCC, verbally agreed to have his real name used in the study. All the team members also allowed me to observe the meetings for my research and to analyze all email correspondence.

The study took place in the months of October and November of 2011. Participant observation primarily took place at the office of a local non-profit organization in Downtown Vancouver; this was the primary meeting place for the OCC team who met every Sunday. During the time of the study, I was an active member of the OCC team and thus, I was already a participant and the observation was a natural fit for my research. Notes were written on what was said and the issues that were discussed, whether they directly related to my research or not. Each meeting would last between one to three hours depending on the agenda. Over the course of two months, all ten members of the OCC team were present at one time or another. The majority of the information here revolved around administrative issues rather than substantial themes relating to the posters. However, the observations gave me a glimpse of how the team planned to promote the posters in various communities and how they responded to people's reactions. I also attended a presentation from Ho at the 7th Annual Gay Men's Health Summit in Vancouver, BC. This presentation presented the goals of OCC's posters as well as its mission to raise awareness of LGBTQ people and issues to the general public. After the presentation, there was a question and answer period that provided further reactions to the posters for my research.

Archival data analysis was also utilized as I had access to all the email correspondence by the team. Google Groups was used for sending messages to each other and I analyzed over one hundred conversation threads to determine which messages were relevant to my topic. This method provided insight on how members of the team viewed various topics. There were also a number of debates amongst team members, which offered different perspectives for me to consider. It gave me a more concrete idea of how the team wanted their posters to be perceived as it provided a glimpse of what the team thought throughout the year, rather than at a specific time (compared to interviews). There were also instances when team members would change their opinions on a particular subject over the course of the year.

To gain more insight, I conducted a focus group with the OCC team to examine the rationale behind the team's decisions. This provided deep discussions surrounding the ideas behind the creation of the posters and the message that the team wanted to convey. There was also an opportunity for me to witness how the team reacted to the online materials regarding the posters. As OCC was a grassroots project at the time without a membership, the team represented the majority of people involved in creating the poster campaign. I also conducted a semi-structured interview with Ho, the leader of OCC. With this interview, 
we discussed the issues that came up when the posters were being created and how he wanted the posters to be perceived by others. We also discussed why Ho created OCC and what he hoped to achieve with the posters.

To gauge the perception of the posters from people outside the OCC team, I conducted several interviews, hosted a focus group, and analyzed Facebook content and news articles. It is important to note that all the participants in the interviews and focus group are from a convenience sample; I personally knew each participant and had already built rapport and trust with them. The topic of LGBTQ issues can be quite sensitive for some people and it is important that this study elicits honest answers rather than answers that are politically correct. Given the short timeline of the study (i.e., two months), I did not feel that it would be fruitful for me to interview strangers as I do not believe the participant would disclose their opinion if the participant held anti-LGBTQ views. As a researcher, I would like to hear those anti-LGBTQ views and if the participant did not feel comfortable disclosing them, the interview would not be useful. In all my interviews, I made sure to ask about the community's attitudes rather than the participant's attitudes. This prevents the possibility that the participant becomes defensive about their own opinions. If they do hold anti-LGBTQ views, they can project their opinions on to the community as a way to avoid judgement. This also limited emotional harm for participants as the questions never referred to intimate, personal details about the participant. In addition, the use of convenience sampling offered a safe environment for me as it limited the likelihood of a violent or dangerous reaction to the questions. If participants felt any degree of harm after the interviews or focus groups, I let them know that I was available to talk about their feelings and offered contact information for organizations and support groups in the community.

The interviews were a mixture of structured, semi-structured, and photo-elicitation. I conducted a structured interview with a heterosexual, female SFU student regarding her community's attitudes toward LGBTQ people and issues, as well as her thoughts on the OCC posters. I also conducted two other semistructured interviews: one with a 24 year-old, gay Persian male and one with a community leader in a Vancouver neighbourhood. These interviews had two main components: first I asked the participants to talk about their community's perception and attitudes toward LGBTQ issues and people, and second, what they thought of the poster. One photo elicitation interview was also conducted with a 23-year-old, gay Filipino male. I presented each poster and asked him to vocalize what came to his mind. After, I asked several general questions about the posters and how he thinks the posters will be perceived. Photo elicitation was included in all my other interviews with participants outside of the OCC team as it gave me a sense of how people outside of OCC perceived the posters.

The focus group consisted of non-LGBTQ friends I knew in high school. My existing rapport with them, and with one another, allowed the focus group to discuss the sensitive topic of LGBTQ issues without awkwardness or hesitation. Participants were able to converse naturally as all of them were acquainted with each other before the focus group was conducted. The existing rapport assisted in creating safe space which allowed for honest discussion on LGBTQ topics and reduced the likelihood of harmful comments between participants.

Lastly, content analysis of materials, like news articles, Facebook posts and comments, radio interviews, and TV stories was conducted to further gain a sense of how people outside the team perceived the posters. This method provided additional critical perceptions of the posters as online media tends to contain many comments without having to interview individuals from all over the place. With the anonymity of the internet, commenters may feel more comfortable sharing their opinions. In addition, journalists tend to highlight what they think are the most important issues, which aided in identifying important themes. This method helped balance the interviews as it provided critical reactions to the posters that may not have emerged in a safe environment.

\section{MODE OF ANALYSIS}

I started the analysis by writing notes on all the data available. From these notes, I conducted open coding where I wrote down any codes that came to mind. After listing all the codes, I picked the ones that seemed to be the most important. Importance was measured both quantitatively and qualitatively. Codes that came up often in the data were seen to be significant. In addition, I also asked the participants what they felt were important themes and news articles also assisted in highlighting what the journalists thought were important issues. These selected 
codes were then combined to form general themes. With these themes in mind, I went back to the data to ensure I gathered all the relevant evidence. I wrote several memos regarding the themes and lastly, incorporated them into a paper.

\section{FINDINGS AND DISCUSSION}

The focus on ethnic communities (as part of linguistic and cultural communities) with the OCC posters meant that the team had to have a clear definition of what exactly constitutes ethnicity. Ho, who identifies as Chinese, states that ethnic in the context of the posters refer to "the four cultural community groups we are targeting [i.e., Chinese, Korean, Persian, and Punjabi]" (OCC focus group, Nov. 6, 2011). The member meaning of ethnicity is very specific and caters to the needs of the team. However, during the one-on-one interview, Ho recognizes that the term ethnic is a rather vague term as "everyone is ethnic" (semi-structured interview, Oct. 28, 2011). It can refer to visible minorities, racialized groups, non-White communities, or other groups. The team eventually decided to stick with the term ethnic as it is the most efficient way to describe their target audience. In addition, it is a word that many people are familiar with and can understand.

Moreover, the OCC team mentioned in the focus group that ethnicity could refer to either people who are not White or people who identify as ethnic or visible minority. The other issue is whether ethnic communities can be easily distinguished from a White community. One participant, a 21-year-old Asian SFU student in the non-LGBTQ focus group, believes it is hard to separate between the two communities. She rationalizes this by noting how "it's not like...I'm immersed in a completely ethnic community and then I walk over across the street and then I go and hang out with all the White people" (non-LGBTQ focus group, Nov. 12, 2011). As a multicultural country, Canada is home to numerous communities with a mixture of various ethnicities and cultures. This can make it hard to truly define what constitutes an ethnic community for this poster campaign. In the posters, all the models self-identified with the communities listed as OCC's target audience for the posters (i.e., Chinese, Persian, and Punjabi; no Korean poster has been made so far).

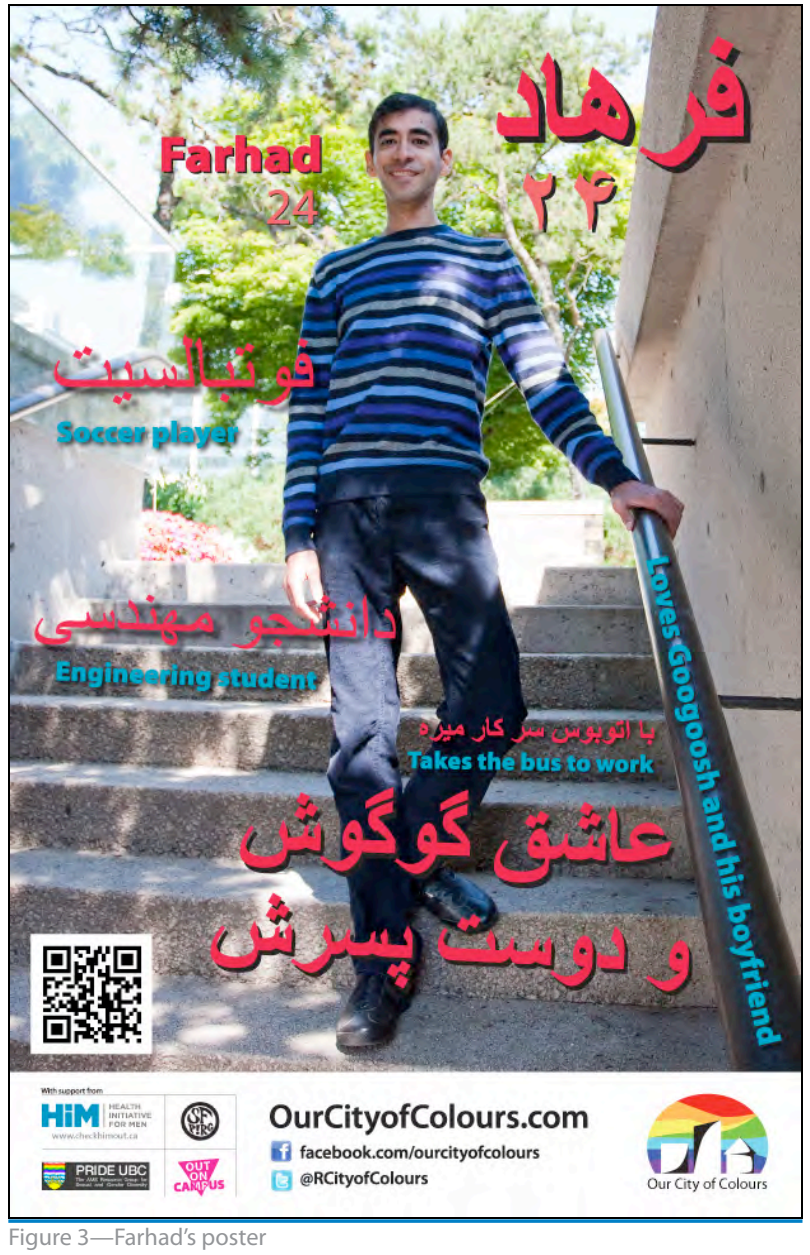

When talking about any community, it is hard not to talk about culture. The OCC team made a conscious effort to incorporate cultural references into their posters whether that be mentioning Googoosh, a cultural icon in Iran or the Chinese holiday, Mid-Autumn Lantern Festival (all names and phrases on the poster are fictional). Yet, Mirza $^{1}$ (a pseudonym), a 24-year-old Persian fashion model, believes "there's nothing to relate to the culture except for maybe the fact that you've used their ethnic writing [language] on the posters" (semi-structured interview, Nov. 15, 2011). He suggested that models in the poster need to wear some sort of cultural dress or be immersed in a cultural background to further convey the point that the posters 


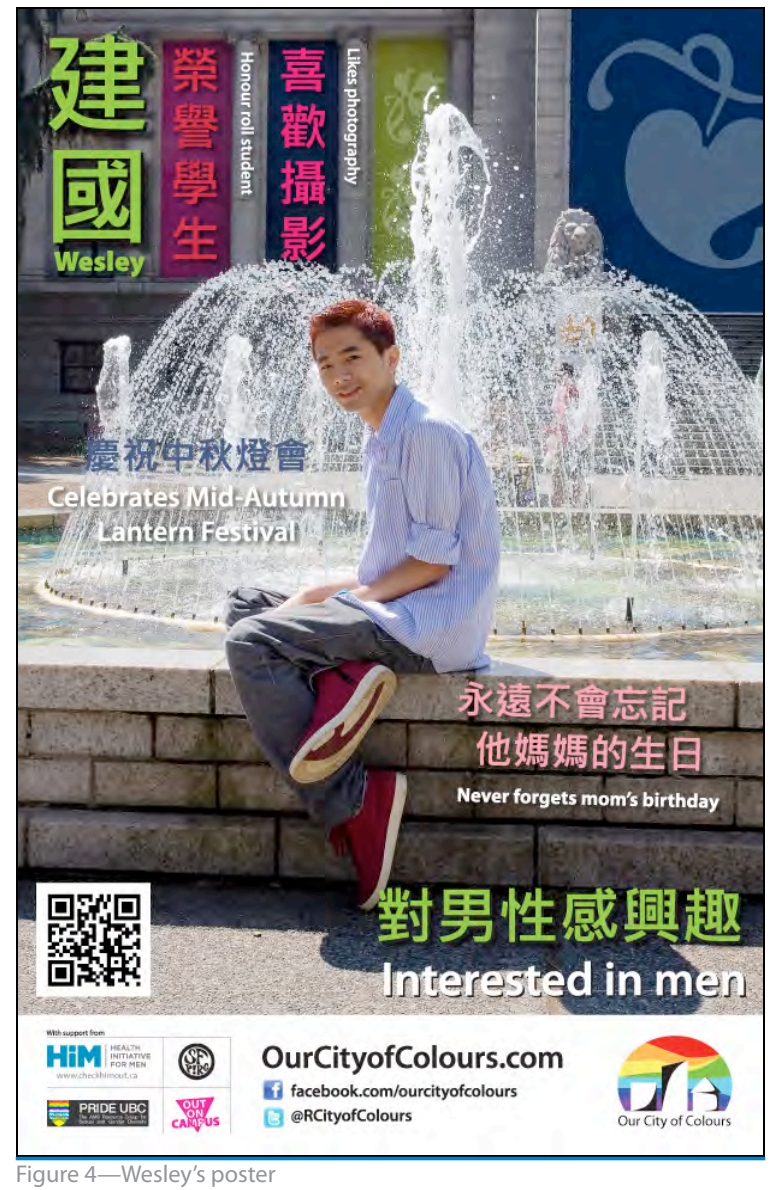

are meant for certain ethnic communities.

However, Craig Takeuchi, a reporter with the Georgia Straight (a free weekly Vancouver newspaper), talked to Alex (Amar) Sangha, the founder of Sher Vancouver, a LGBT organization for South Asians. Sangha "points out that because Ajay isn't wearing a turban, doesn't have a beard, and isn't in traditional costume, this image may moderate any controversy the image will have" (Takeuchi 2011a). This statement is in line with what OCC wants: they do not wish the posters to alienate ethnic communities by relying on stereotypes to describe a culture. Yet, Mirza insists his parents' generation, which he sees as the target audience, already possess stereotypes of how

certain cultures should look. Furthermore, he argues that "immigrant parents... don't want to lose their culture" and feel that their children are losing their culture when adopting Western values and clothes (semi-structured interview, Nov. 15, 2011). Because of this, Mirza believes that immigrant parents may not be able to identify with the models who are dressed in Western clothing; the inclusion of cultural dress and symbols could help alleviate this problem. Although none of the participants were confused as to the target audience being the ethnic community, the majority of the participants were under the age of 25. Only one participant, a community leader in Vancouver, was over the age of 25 and she has a gay son, which may influence how she 


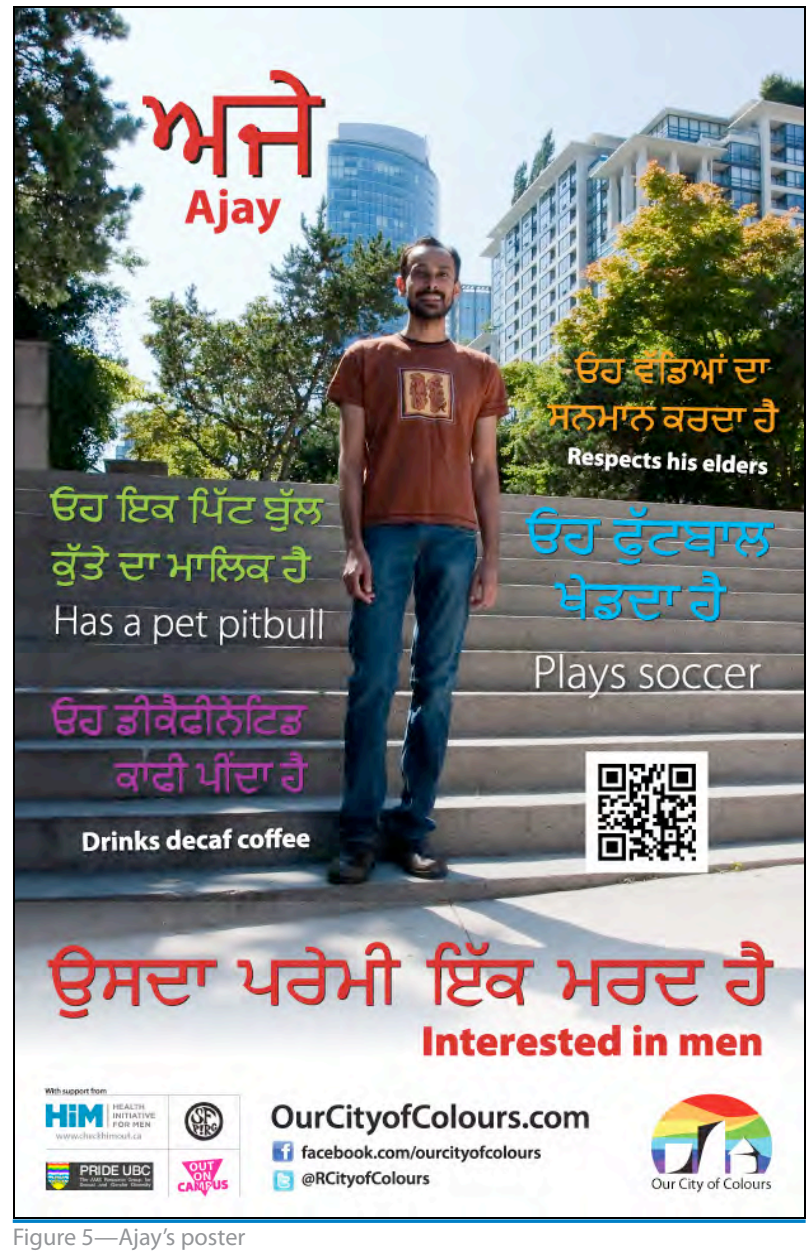

perceived the posters.

Another issue that arose, mainly from Facebook comments, was the idea of Western society imposing values of tolerating, accepting, and respecting LGBTQ people onto ethnic communities. Jason Bryan, in two Facebook comments posted in response to a Georgia Straight article on OCC on November 2, 2011, plays devil's advocate by posing the problem that if Canada is a multicultural country, then Canada should "accept people's intolerance as part of their culture". Bryan suggests that people may feel that if OCC is "doing these widespread campaigns to change social perceptions, then [OCC is] watering down the other cultures and bringing more commonality to [different] cultures" which effectively leads to an "American melting pot". The OCC team decided to not engage with Bryan's comments as the consensus amongst the team was that OCC cannot be responsible to respond to every negative or critical comment about the campaign (OCC focus group, Nov. 6, 2011). It could discredit the group if they decided to wade into every debate brought forward to them. There is also the issue of whether negative reactions are directed towards the posters specifically or if they simply reiterate debates about LGBTQ people in general. The team wants to focus on feedback regarding their mandate of raising awareness and providing positive messages and images of LGBTQ people in linguistic and cultural communities. Although the question of cultural imposition is an interesting concept, the team has identified an issue (the lack of awareness of LGBTQ people and issues) in various linguistic and cultural communities, and it is an issue that needs to be addressed.

Bryan's comments raise an excellent point of how criticisms against the OCC posters cannot be categorized as simply homophobic or racist; instead, the criticisms may take on several discriminatory attitudes at the same time. He suggest that some people may wonder if "the [Chinese] community does not want to accept certain lifestyles, should the [Western], white liberals force their beliefs of tolerating anything onto [the Chinese community]"? Ultimately, the OCC posters could be seen as "forcing [Western], white liberal culture of tolerance onto the Chinese conservative culture". These questions and ideas contains elements of heterosexism and racism as it assumes and generalizes that another culture is homophobic and thus, should be left alone as it is part of their values. People that believe homosexuality is a lifestyle delegitimize LGBTQ people by viewing sexual orientation as a choice rather than a lived experience. In addition, the Chinese community cannot be generalized to be conservative as it does not acknowledge the wide range of ideological beliefs found within the Chinese community. The idea presented in Bryan's comments contains homophobic views on top of a sweeping racist assumption that intersect to form the basis for the issue presented. With these posters, OCC challenges this intersection of multiple discriminatory attitudes fueling the hypothetical criticisms found in Bryan's comments.

The last theme that came up in my research was the role language plays in how the posters are interpreted. In an interview with Craig Takeuchi, Ho explains that the word 'gay' is 
never used in any of the posters because certain cultures have acquired negative connotations with the word 'gay' (Takeuchi 2011c). As a linguistic student, Ho understands the intricacies of how language evolves and changes throughout time, with certain derogatory words (e.x., like queer) requiring years to be reclaimed as positive words (email communication, Nov. 9 2011). One important goal for the OCC posters is to provide an opportunity for communities to begin to associate LGBTQ people with positive images and descriptions. Ho emphasizes this point at the 7th Annual Gay Men's Health Summit, a conference focusing on gay men's health. During a presentation and panel on young gay men's health, Ho commented how he wanted the community to see the images on the posters first before automatically thinking of a word to describe the relationship. If the word appears first, then the reader may conjure stereotypical and negative thoughts before seeing the rest of the poster. By placing the LGBTQ tagline at the bottom, it limits the opportunity for the reader to come up with prejudices regarding LGBTQ people. In addition, all the posters describe the relationship rather than impose a label on them. The lack of labelling in the posters allow communities to hopefully come up with their own positive words to describe the relationship (Christopher 2011).

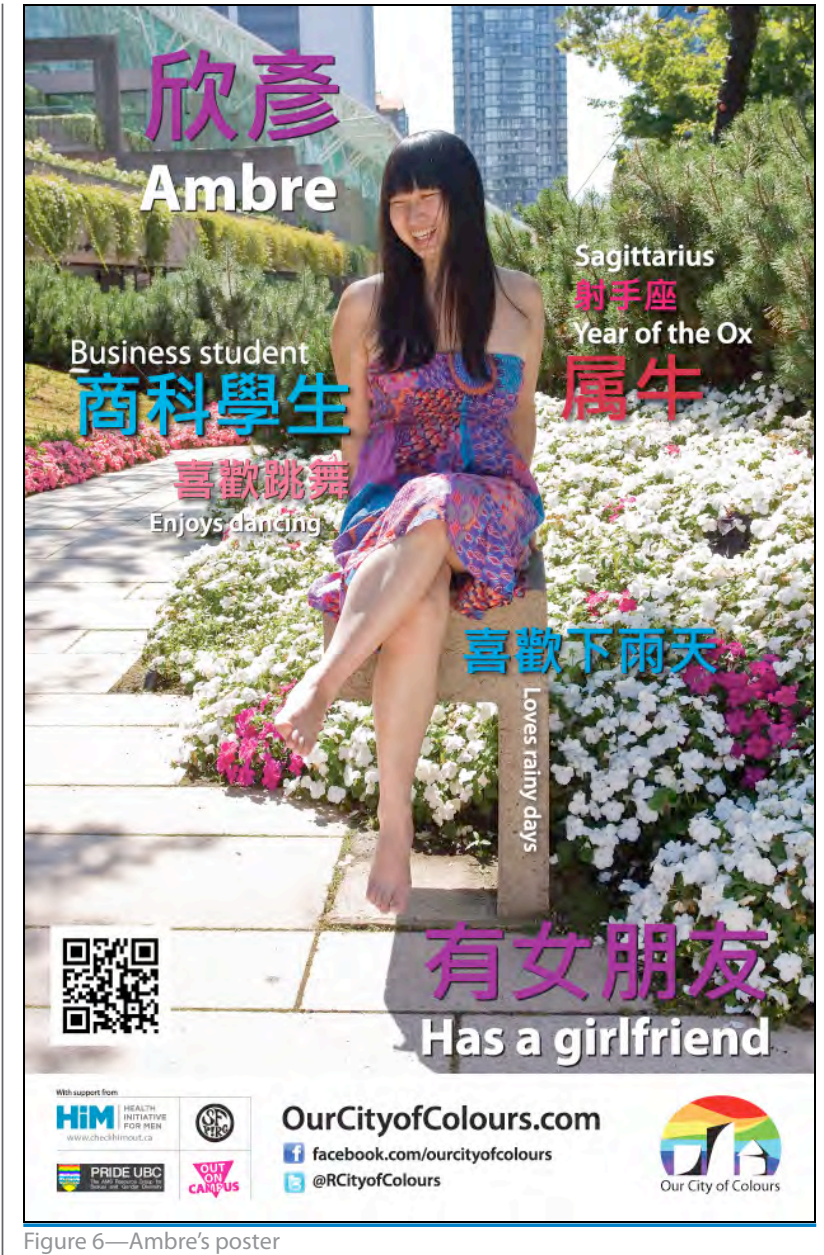

However, by describing the relationships rather than labelling them, the posters may convey a weaker LGBTQ message than intended. Takeuchi, a supporter of OCC, notes that the Ambre poster's use of 'girlfriend' is "less obvious that it implies an intimate same-sex lover" (Takeuchi 2011b). He suggests that viewers of the posters may have to visit OCC's Facebook page in order to understand the LGBTQ message in the poster. Sarah ${ }^{4}$ (a pseudonym), a community leader in Vancouver who was born in Chile, believes the posters featuring a single person communicate a subtler LGBTQ message. Yet, she sees this as an asset as these posters could be a way to slowly introduce the topic into 
the community. For future campaigns, Sarah thinks the posters could evolve into something more romantic (semi-structured interview, Nov. 26, 2011). Mirza completely disagrees with Sarah on this point. He is adamant that OCC, as a new group, must create shocking and passionate posters in order to stand out. Instead of having models holding hands, Mirza believes an extra step needs to be taken, like having the models kiss or be on an intimate date. He argues that the current posters featuring a couple could be interpreted as a friendship rather than a romantic relationship, especially when friends holding hands is common in Asian culture (semi-structured interview, Nov. 15, 2011). Thus, OCC may want to maintain a balance of conservative and more romantic posters to appeal to a diverse range of audiences.

\section{LOOKING AHEAD}

The purpose of the OCC posters is to raise awareness by providing positive messages and images of LGBTQ people and issues in a variety of linguistic and cultural communities. Ideally, linguistic communities, cultural communities, and LGBTQ communities will undergo the process of acculturation to understand and adapt to each other's needs. These posters are seen by the team as an initial attempt in changing anti-LGBTQ attitudes held by various communities through engaging community members in discussions on the topic.

In general, the OCC posters were viewed by the participants as something that had never existed before in Metro Vancouver. Described as a "taboo-busting" campaign (Takeuchi 2011d), nearly all the participants agreed that at the very least, the posters will catch the attention of people because it is a campaign that is unique by directing a sensitive subject to linguistic and cultural communities. However, more attention may be required to ensure that the LGBTQ message is conveyed. The team's decision to describe the relationship rather than impose labels is sensitive to cultural needs, but comes at the cost of having a clear, concise message, which could be balanced with a more romantic image. In addition, the OCC team may wish to incorporate more cultural references to appeal to the older generation. Many participants viewed older generations as the main audience since the younger generations tend to be more aware of LGBTQ people and issues. As such, the OCC team may want to direct future posters specific to older generations.

The poster campaign tackles an issue that goes beyond only heterosexism or racism; instead, it approaches the intersection of where heterosexism meets racism. It is a process involving the shifting of attitudes towards LGBTQ people in various communities and it will be a long, but important journey requiring considerations for various cultures. Our City of Colours is taking the first of many steps to create an understanding, respectful, and inclusive society for all cultures and communities. 


\section{REFERENCES}

Abraham, Ibrahim. 2009. "'Out to get us': Queer muslims and the clash of sexual civilisations in australia." Contemporary Islam 3 (1): 79-97.

Berry, John W. 2005. "Acculturation: Living successfully in two cultures." International Journal of Intercultural Relations 29 (6): 697-712.

Boulden, Walter T. 2009. "Gay hmong: A multifaceted clash of cultures." Journal of Gay \& Lesbian Social Services 21 (2-3): 134-50.

Chan, Connie S. 1989. "Issues of identity development among asian-american lesbians and gay men." Journal of Counseling \& Development 68 (1): 16-20, http://search.ebscohost.com/login.asp $x$ ?direct $=$ true $\& d b=b$ th $\& A N=5334087 \&$ site $=$ ehost-live.

Christopher, Nathaniel. 2011. “Gay posters for chinese, iranian and punjabi communities.” Xtra!, November 10. http://www.xtra.ca/public/Vancouver/Gay_posters_for_Chinese_Iranian_ and_Punjabi_communities-11061.aspx.

Chung, Y. B., and Dawn M. Szymanski. 2006. "Racial and sexual identities of asian american gay men." Journal of LGBT Issues in Counseling 1 (2): 67-93, http://www.tandfonline.com/doi/ abs/10.1300/J462v01n02_05.

Etter, Jean-François, and Evelyne Laszlo. 2005. “Evaluation of a poster campaign against passive smoking for world no-tobacco day." Patient Education and Counseling 57 (2) (May): 190-8.

Gallor, Susanna M., and Ruth E. Fassinger. 2010. “Social support, ethnic identity, and sexual identity of lesbians and gay men." Journal of Gay \& Lesbian Social Services 22 (3): 287-315, http:// dx.doi.org/10.1080/10538720903426404.

Han, Chong-suk. 2007. "They don't want to cruise your type: Gay men of color and the racial politics of exclusion." Social Identities 13 (1): 51-67, http://search.ebscohost.com/login.aspx?direct $=$ true $\& \mathrm{db}=\mathrm{aph} \& \mathrm{AN}=24078221 \&$ site $=$ ehost-live.

Hooghe, Marc, Ellen Claes, Allison Harell, Ellen Quintelier, and Yves Dejaeghere. 2010. "Anti-gay sentiment among adolescents in belgium and canada: A comparative investigation into the role of gender and religion." Journal of Homosexuality 57 (3): 384-400, http://www.

This work is licensed under a Creative Commons AttributionNonCommercial-

NoDerivs 3.0

Unported License. informaworld.com.proxy.lib.sfu.ca/10.1080/00918360903543071.

Hooghe, Marc, Yves Dejaeghere, Ellen Claes, and Ellen Quintelier. 2010. “Yes, but suppose everyone turned gay?: The structure of attitudes toward gay and lesbian rights among islamic youth in belgium." Journal of LGBT Youth 7 (1): 49-71, http://www.informaworld. com.proxy.lib.sfu.ca/10.1080/19361650903507916. 
Lui, Camillia, Salman Husainy, Rashmi Choksey, Joyti Chand, Prajna Paramita Choudhury, Sanjay Chhugani, Neetu S. Badhan, and Eric C. Wat. 2009. "Community alienation and its impact on help-seeking behavior among LGBTIQ south asians in southern california." Journal of Gay \& Lesbian Social Services 21 (2/3): 247-66.

Mao, Limin, John Mccormick, and de Ven Van. 2002. “Ethnic and gay identification: Gay asian men dealing with the divide." Culture, Health \& Sexuality 4 (4): 419-30, http://www.tandfonline. com/doi/abs/10.1080/13691050110148342.

Mireshghi, Sholeh I., and David Matsumoto. 2008. "Perceived cultural attitudes toward homosexuality and their effects on iranian and american sexual minorities." Cultural Diversity and Ethnic Minority Psychology 14 (4): 372-6.

Moreau, Jennifer. 2011a. "Parents protest gay-positive policy." Burnaby Now, April 30. http://www. burnabynow.com/news/Parents+protest+positive+policy/4703819/story.html.

2011b. “Anti-homophobia policy sparks parents' protest; group says board's stance infringes on morality." The Province, June 28. http://www2.canada.com/theprovince/news/ story.html?id=a958083e-55a9-476a-8f38-e8795bbe4cad.

O'Neill, Brian. 2011. “Diversity within diversity: Settlement experiences of lesbian, gay and bisexual newcomers in BC." (presentation, National Metropolis Conference 2011, Vancouver, BC, March 23, 2011).

Our City of Colours. 2011. "Our city of colours." Accessed October 1. https://www.facebook.com/ ourcityofcolours.

Potter, Sharyn J., Mary M. Moynihan, Jane G. Stapleton, and Victoria L. Banyard. 2009. “Empowering bystanders to prevent campus violence against women." Violence Against Women 15 (1): 106-21.

Pulley, Jill, Margaret Brace, Gordon Bernard, and Dan Masys. 2007. “Evaluation of the effectiveness of posters to provide information to patients about a DNA database and their opportunity to opt out." Cell and Tissue Banking 8 (3): 233-41.

Saarela, Kaija Leena. 1989. "A poster campaign for improving safety on shipyard scaffolds." Journal of Safety Research 20 (4): 177-85.

Szymanski, Dawn M., and Arpana Gupta. 2009. “Examining the relationships between multiple oppressions and asian american sexual minority persons' psychological distress." Journal of Gay \& Lesbian Social Services 21 (2-3): 267-81, http://www.tandfonline.com/doi/ abs/10.1080/10538720902772212. 
Takeuchi, Craig. 2011a. "Making LGBT people visible in the south asian community: Our city of colours, sher vancouver, and more." Straight.com Blogra, November 18. http://www. straight.com/article-543951/vancouver/lgbt-presence-south-asian-community-our-citycolours-sher-vancouver-and-more.

___. 2011b. "Our city of colours challenges lesbian invisibility in chinese canadian community." Straight.com Blogra, November 7. http://www.straight.com/article-525041/vancouver/ our-city-colours-challenges-lesbian-invisibility-chinese-canadian-community

__— 2011c. "Our city of colours illuminates the LGBT rainbow in ethnic communities." Straight. com Blogra, August 31. http://www.straight.com/article-443476/vancouver/outpost-ourcity-colours-aims-illuminate-lgbt-rainbow-people-colour.

. 2011d. "Our city of colours shatters LGBT visibility barrier in chinese canadian community." Straight.com Blogra, November 1. http://www.straight.com/article-518706/vancouver/ our-city-colours-breaks-lgbt-visibility-barrier-chinese-canadian-community

Teney, Céline, and S. V. Subramanian. 2010."Attitudes toward homosexuals among youth in multiethnic brussels." Cross-Cultural Research 44 (2): 151-73. 